\title{
Snapshot
}

\section{Orbital sinker}
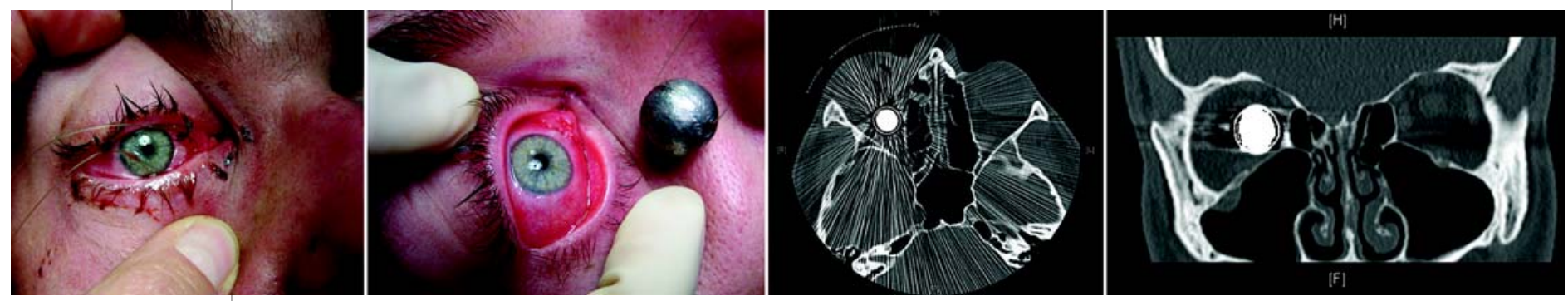

A 21-year-old man sustained a high-velocity injury to his right orbit by a sinker, when his fishing line suddenly released from trapped vegetation.

There was a medial canalicular laceration and inferonasal conjunctival entry wound with fishing line visible. Computed tomography showed the sinker lodged medially, deep within the orbit. There were no fractures and the globe appeared intact.

In theatre, the sinker was pulled through the conjunctival Online first 24/10/11 laceration using the fishing line and the canaliculus repaired.
Visual acuity was $6 / 6$ postoperatively. There was a small nasal choroidal rupture and vitreous haemorrhage, but no major visual sequelae. Jennifer J Danks Visiting Medical Officer Department of Ophthalmology, Sydney Eye Hospital, Sydney, NSW. jennydanks@optusnet.com.au

doi: $10.5694 /$ mjall.11204
Esra Sanli Senior Resident Medical Officer 